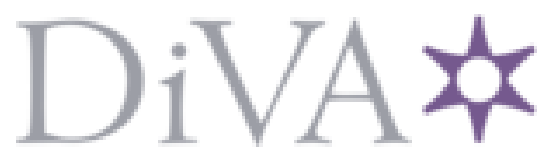

http://www.diva-portal.org

\title{
Postprint
}

This is the accepted version of a paper published in Journal of Fish Biology. This paper has been peer-reviewed but does not include the final publisher proof-corrections or journal pagination.

Citation for the original published paper (version of record):

Nissling, A., Larsson, R. (2018)

Population specific sperm production in European flounder Platichthys flesus:

Adaptation to salinity at spawning

Journal of Fish Biology, 93(1): 47-52

https://doi.org/10.1111/jfb.13667

Access to the published version may require subscription.

N.B. When citing this work, cite the original published paper.

Permanent link to this version:

http://urn.kb.se/resolve?urn=urn:nbn:se:uu:diva-36406o 


\section{Population specific sperm production in flounder Platichtys flesus - adaptation to salinity at} spawning

A. Nissling ${ }^{\mathrm{a}^{*}}$, R. Larsson ${ }^{\mathrm{b}}$ (1)

${ }^{a}$ Ar Research Station, Department of Ecology and Genetics, Uppsala University, SE-621 67 Visby, Sweden, ${ }^{\mathrm{b}}$ Institute of Marine Research, SLU Aqua, SE-453 21 Lysekil, Sweden

*Author responsible for correspondence: Anders Nissling. Tel.: +46 (0)498 224630; e-mail: anders.nissling@ebc.uu.se

(1)
(1) Running headline: ADAPTATION OF SPERM PRODUCTION IN P. FLESUS

Pre-printed manuscript of article published in Journal of Fish Biology wileyonlinelibrary.com/journal/jfb

Please cite this article as: Nissling, A. \& Larsson, R. (2018). Population specific sperm production in flounder Platichtys flesus - adaptation to salinity at spawning. Journal of Fish Biology 93, 47-52. DOI: 10.1111/jfb.13667 (Accepted: 19 April 2018). 
Marine teleosts inhabiting the brackish water Baltic Sea have adapted to the less saline water with activation of spermatozoa at low salinity hypo-osmotic conditions but with shorter longevity and lower swimming speed that affect the fertilization capacity. Aiming to elucidate if the fertilization capacity may be maintained by increasing the number of spermatozoa produced, testis size for the euryhaline flounder Platichtys flesus with external fertilization was assessed along a salinity gradient; with spawning at a salinity of $\approx 7,10-18$ and 30-35. Fulton's condition factor (100 somatic fish mass total fish length ${ }^{-3}$ ) averaged $0.881 \pm 0.085$ (mean \pm S.D.), $0.833 \pm 0.096$ and $0.851 \pm 0.086$, for fish spawning at $\approx 7,10-18$ and 30-35, respectively, with no difference between areas, i.e. analysed fish were in similar nutritional condition. A general linear model, with testes dry mass as dependent variable and somatic mass as covariate resulted in a significant difference between areas/populations with larger testes for $P$. flesus spawning at a salinity of $\approx 7$ but no difference between fish spawning at a salinity of 10-18 and 30-35. The result suggests that adaptation by increasing the number of spermatozoa produced may be a key mechanism for marine teleosts spawning in areas with low salinities to sustain the fertilization capacity as shown here for the euryhaline P. flesus. 
A prerequisite for fishes to inhabit an area is the potential to reproduce, i.e. the distribution is restricted by the ability to cope with environmental conditions at spawning. Hence, adaptations for reproduction have evolved and continue to evolve in response to local environmental conditions. Accordingly, preferences for, or tolerances to, environmental parameters such as salinity vary amongst species, and amongst populations within species given the wide range of habitats utilized by fishes (e.g. Wootton, 1990).

To accomplish successful reproduction activation of the spermatozoa is crucial for fertilization. The spermatozoa remain quiescent in the testes and seminal plasma at isotonic conditions $(\approx 300 \mathrm{mOsm} \mathrm{kg}$ ${ }^{1}$; corresponding to a salinity of $\approx 10$ ) prior to the release into the water when motility is triggered by the hypo- or hyperosmotic conditions in freshwater- and marine species, respectively (e.g. Morisawa \& Suzuki, 1980; Stoss, 1983; Billard, 1986; Alavi \& Cosson, 2006). For marine fishes, spermatozoa activation occurs at discharge in high saline water, 30-35, triggered (as shown for at least some species) by an efflux of water from the spermatozoa to the hyperosmotic environment which results in an elevated internal concentration of calcium ions $\left(\mathrm{Ca}^{2+}\right)$, and initiation of motility (e.g. Cosson et al., 2008; Boj et al., 2015). Thus, salinity/osmolality and/or concentrations of specific ions are determinant factors for spermatozoa activation and fertilization capacity in fishes. Some marine fishes inhabit and reproduce also in brackish water with adaptation of spermatozoa motility to low salinities (see below). Although the mechanism is yet not fully understood this represents an interesting challenge concerning the evolution of coping with low osmotic differences between the internal and external osmolality and adaptation of spermatozoa motility. Spermatozoa motility is additionally under the influence of maternal factors (egg/ovarian fluid) enhancing both the swimming speed and the proportion of motile sperm as shown for the marine Atlantic cod, Gadus morhua L. (Litvak \& Trippel, 1998). However, the effect ceased at low salinities (salinity of 15; see Litvak \& Trippel, 1998), 
Westin, 1997). This suggests that the initiation of spermatozoa motility is still governed by salinity/osmolality and/or concentrations of specific ions.

The capacity for fertilization is a question of spermatozoa longevity and speed and direction of swimming as well as the number of spermatozoa activated. Aiming to assess the relative importance of spermatozoa motility vs the number of spermatozoa produced in relation to intensity of sperm competition (i.e. in relation to spawning behaviour as internal/external fertilization, polygamy/monogamy, communal spawning/distinct pairing) Stockley et al. (1997) found an increase in both spermatozoa numbers and relative testes mass ( $c f$ gonado-somatic index) with intensity of sperm competition across species, i.e. as an adaptation to increase the fertilization capacity. Similarly, Awata et al. (2008) found an increase in the relative testes mass as an adjustment to sperm competition risk in the cichlid Julidochromis transcriptus (Matthes 1959) with polyandrous males producing larger testis compared to monogamous males. Stockley et al. (1997) ranked intensity of sperm competition for several teleost species based on spawning behaviour. Flounder Platichtys flesus L. was given a low rank, i.e. low sperm competition, as spawning in pairs (Table I in Stockley et al., 1997).

For marine fishes to reproduce at low salinities, adaptations are required as both fertilization and egg development is affected at low salinities as shown for teleosts inhabiting the brackish water Baltic Sea (Solemdal, 1970; Westin \& Nissling, 1991; Nissling et al., 2002; 2006), with salinities ranging from 3 to 9 in the surface water and between 10-20 in the deep basins below the halocline (see Voipio, 1981). Only a few fish species of marine origin have succeeded in colonizing the Baltic Sea, with adaptations of spermatozoa motility and egg characteristics that are considered population specific (Solemdal, 1973; Thorsen et al., 1996; Nissling \& Westin, 1997).

Platichtys flesus inhabit both marine and brackish waters in coastal waters of the Eastern Atlantic from the White Sea to the Mediterranean and the brackish water Black Sea and Baltic Sea (FishBase, 2017) with spawning occurring at salinities ranging from 6-7 to 30-35. In the Baltic Sea two genetically distinct $P$. flesus ecotypes (Hemmer-Hansen et al., 2007; Florin \& Höglund, 2008) with different spawning strategies occur; spawning pelagic eggs in offshore deep basins below the permanent 
halocline at a salinity of 10-20 and demersal eggs in coastal areas and on offshore banks at 6-9

(Nissling et al., 2002; 2015; Ustups et al., 2013). For a more thorough description of salinity conditions in the Baltic Sea as well as spawning areas of $P$. flesus see e.g. Voipio (1981) and Nissling et al. (2002). In P. flesus spermatozoa activation occur at a salinity of $\geq 9-10$ for the ecotype spawning in the deep basins and at $\leq 3$ for the type spawning in coastal areas and on offshore banks vs at a salinity of $\approx 11$ for P. flesus at marine conditions off Bergen, Norway in the North Sea (Solemdal, 1970; Nissling et al., 2002). However, spermatozoa motility is affected at low salinities with significantly shorter longevity and lower swimming speed (for methodology see studies on turbot Scophthalmus maximus L.; Nissling et al., 2006) at a salinity of $\leq 11-12$ and $\leq 7$ for the deep basin- and the coastal spawning P. flesus ecotype respectively, with a decrease in fertilization (Nissling et al., 2002; observations in the present study). A more thorough overview of variability in salinity conditions and effects on the reproductive success of $P$. flesus in the Baltic Sea, with implications for spatial distribution and variability in stock abundance is given in Nissling et al. (2002) and in Ustups et al. (2013).

As given above both spermatozoa longevity and swimming speed decrease significantly with decreasing salinity affecting the fertilization rate in P. flesus. Hence, to compensate for decreased motility in marine fishes when spawning at low salinities, the fertilization rate may be maintained by increasing the number of spermatozoa produced. Aiming to elucidate the effects of salinity on adaptive reproductive strategy we assessed testes size in the euryhaline $P$.flesus with external fertilization, along a salinity gradient; spawning occurring in marine water at $30-35$, at brackish water at $15-18$, at $10-12$ and at $\approx 7$, i.e. potential adaptation of spermatozoa production in relation to salinity at spawning.

\section{MATERIAL AND METHODS}

Fish were caught during spawning, by trawling at Lilla Middlegrund and Morups Bank in Kattegat (ICES SD 21) at 40-50 m depth in March 2015 and 2016, and in the Baltic Sea using gill-nets with 
different mesh sizes in the Hanö Bight (SD 25) at ₹70 m depth in April 2015, and off Gotland (SD 28) at both 50-70 m and 10-20 m depth in April 2015 and 2016 using gill-nets with different mesh sizes (Fig. 1). Individuals in stage 3 (ICES, 2010), i.e. in running condition (milt flows at light pressure) were sampled and frozen. For fish sampled in SD 25 and SD 28, where both P. flesus ecotypes occur (Nissling et al., 2015), determination of ecotype based on spermatozoa motility in different salinities (see Nissling et al., 2002) was performed before being frozen. Spermatozoa motility was assessed at $250 \mathrm{x}$ magnifications under a microscope at a salinity of $15,10.5,7.5$ and 6 respectively, at $7{ }^{\circ} \mathrm{C}$. Individuals with swimming spermatozoa at both $10.5-15$ and at 6-7.5 were considered coastal spawners (ecotype with demersal eggs) as opposed to individuals displaying swimming spermatozoa at 10.5-15 only considered deep basin spawners (ecotype with pelagic eggs; see Nissling et al., 2002). For each determination semen was sampled directly from the male using a dry Pasteur-pipette, and for each salinity tested a droplet of semen was diluted in approximately $1 \mathrm{ml}$ water, prepared from Baltic Sea water (salinity $\approx 6.5-7$ ) and synthetic seasalt or by dilution with distilled water, to induce spermatozoa activation. The time from mixing to observation was approximately $5 \mathrm{~s}$. Additionally, the initial motility of swimming spermatozoa was judged at a relative scale; swimming slow, at intermediate speed or fast, to obtain an idea of potential differences in spermatozoa motility between salinities.

The fish were thawed, and total length $\left( \pm \mathrm{mm} ; L_{\mathrm{T}}\right)$, somatic mass $[ \pm 1 \mathrm{~g}$ (intestine and testis removed); $\left.W_{\mathrm{S}}\right]$ and testis wet mass $\left( \pm 0.001 \mathrm{~g} ; W_{\mathrm{TW}}\right)$ measured. Stage of spawning was assessed based on colour and shape of testes, and photographed. Only individuals with testes judged as in early stage 3 were included in analysis, i.e. whitish bulbous testis as opposed to testis with a reddish-greyish cast and with partly flaccid lobes (see images shown as Supporting Information for examples). Dry mass $\left(W_{\mathrm{TD}}\right)$ of sampled testis was measured $( \pm 0.0001 \mathrm{~g})$ after incubation at $60^{\circ} \mathrm{C}$ for $24 \mathrm{~h}$. The relative testes mass ( $c f$ gonado-somatic index; $I_{\mathrm{G}}$ ) was calculated as $100 \mathrm{~W}_{\mathrm{TD}} W_{\mathrm{S}}^{-1}$ and fish condition $\left(C_{\mathrm{F}}\right)$ assessed as

141 in the length-mass relationship for P. flesus males in the Baltic Sea, 2.83, and the North Sea, 2.75 (Fishbase, 2017). 
Analysis included potential differences between fish according to area and P. flesus ecotype; Kattegat (KA), deep basin spawning in the Baltic Sea (BSDS) and coastal spawners in the Baltic Sea (BSCS). For fish sampled in SD 25 and SD 28 (both ecotypes occur) only individuals fulfilling both the criterion: determined according to ecotype based on spermatozoa motility, and caught at expected depth, 50-70 m and 10-20 m, for deep basin- and coastal-spawners respectively, were included in analysis (overlap in distribution of the ecotypes during spawning may occur with potentially hybridisation; see Nissling et al., 2015). Potential differences in $L_{\mathrm{T}}$ and $C_{\mathrm{F}}$ were examined using ANOVA. Differences in $W_{\text {TD }}$ were analysed by a General Linear Model (IBM SPSS Statistics software, version 22; www.ibm.com), with $\log W_{\mathrm{TD}}$ as dependent variable, area/ecotype as fixed factor and $\log W_{\mathrm{S}}$ as covariate, including the interaction between $W_{\mathrm{S}}$ and area/ecotype. The model was run stepwise with subsequent removal of non-significant variables ( $P>0.05$; starting with the highest) until only significant predictors remained.

Positions of sampling sites, dates of sampling and depth range and salinity are given in Table I together with the number of fish analysed.

\section{RESULTS}

Total $L_{\mathrm{T}}$ of analysed P. flesus averaged $27.3 \mathrm{~cm}$ (range 22.8-33.2), $24.9 \mathrm{~cm}(19.7-33.6)$ and $25.1 \mathrm{~cm}$ (19.8-29.4) for fish from KA, BSDS and BSCS respectively with KA fish being significantly larger than fish from BSDS and BSCS $\left(F_{2,101}=10.2, P<0.001\right)$ potentially reflecting the sampling methods (trawling vs caught with gill-nets with different mesh sizes). No difference in fish condition occurred $\left(F_{2,101}=2.07, P=0.131\right) ; C_{\mathrm{F}}$ averaged $0.851 \pm 0.086$ (mean \pm S.D. $), 0.833 \pm 0.096$ and $0.881 \pm 0.085$ for $P$. flesus from KA, BSDS and BSCS respectively, indicating that the fish analysed were in similar nutritional condition. 
Assessed initial spermatozoa motility at different salinities of the coastal- and deep-basin spawning $P$. flesus ecotype, respectively in the Baltic Sea is shown in Fig. 2. Spermatozoa swimming speed decreased with decreasing salinity, e.g. lower initial motility at 6-7.5 vs at 10.5-15 for BSCS fish and somewhat lower motility at 10.5 vs at 15 with no motility at 6-7.5 for BSDS fish, i.e. concomitant to assessment of duration of spermatozoa motility at different salinities as reported in Nissling et al. (2002), spermatozoa motility of $P$. flesus decreases with salinity and differs between the ecotypes.

Testes size, assessed as dry mass, differed significantly between the ecotypes $(P<0.001$; Table II), with larger testes for BSCS fish compared to KA and BSDS fish, and with no difference between BSDS and KA fish ( $P>0.05$; pairwise comparisons). Testes dry mass, evaluated at a somatic mass of 0.149 $\mathrm{kg}$ (Table II), averaged 1.37 (1.20-1.56) g (mean and 95\% C.L.) for BSCS, and 0.51 (0.43-0.60) and $0.46(0.41-0.51) \mathrm{g}$ for BSDS and KA fish respectively. Hence, the outcome yielded significantly larger testes for P. flesus spawning in coastal areas in the Baltic Sea at a salinity of 7-7.5 compared to P. flesus spawning offshore at salinity of 10-18 in the Baltic Sea deep basins and at 30-35 in the Kattegat (Fig. 3). Accordingly, the relative testes mass $\left(I_{\mathrm{G}}\right)$ varied between $0.82 \pm 0.34$ (mean \pm S.D.) for BSCS and $0.31 \pm 0.14$ and $0.31 \pm 0.13$ for BSDS and KA fish respectively, with corresponding values for the relative testes mass calculated using testes wet mass $\left(W_{\mathrm{TW}}\right)$ of $5.7 \pm 1.4,2.4 \pm 1.2$ and $2.0 \pm 0.6$, respectively.

Images of testes size for a $26 \mathrm{~cm}$ P. flesus from KA, BSDS and BSCS respectively is shown as Supporting Information.

\section{DISCUSSION}

Analysis of testes investment of $P$. flesus along a salinity gradient revealed a significant difference in testes dry mass between areas/populations, with larger testis for P. flesus spawning in the Baltic Sea at a salinity of $\approx 7$ compared to fish spawning in the Baltic Sea at a salinity of 10-18 and fish spawning in 
the Kattegat at 30-35.The coefficient of determination in regressions varied between $0.38-0.65$. This may be considered reasonable given that the testes included in analysis represent fish in early stage 3, i.e. intra-area/ecotype variability should be expected as individuals have commenced spawning.

The present study suggests, concomitant to Bagenal's theory about higher fecundity due to harsher conditions affecting reproduction at the borders of a species distribution compared to in the centre (Bagenal, 1966), a similar pattern concerning sperm production. For P.flesus in the Baltic Sea, living at the border of its distribution with respect to salinity, the reproductive success is limited by effects on both fertilization rate and egg development with implications for variability in the spatial distribution and in stock abundance (Nissling et al., 2002; Ustups et al., 2013). For the ecotype spawning in coastal areas at a salinity of 6-9, the reproductive success is sustained by higher sperm production (present study) and higher fecundity (Nissling \& Dahlman, 2010) compared to the ecotype spawning in the deep basins at a salinity of 10-20 as well as populations in marine waters. The coastal spawning P. flesus ecotype displayed significantly larger testes, $1.38 \mathrm{~g}$ (mean) dry mass vs $0.51 \mathrm{~g}$ and $0.46 \mathrm{~g}$ for the deep basin spawning ecotype and in marine water respectively for a $0.149 \mathrm{~kg}$ (somatic mass) fish (present study), and higher fecundity, 1726000 for costal spawners vs 1097000 for deep basin spawners similar to fish in the North Sea in marine water with estimated fecundity of 920000 1245000, for a $35 \mathrm{~cm}$ P. flesus (Nissling \& Dahlman, 2010). Hence, to cope with lower fertilization rates and egg survival when spawning at low salinities, adaptations involve higher allocation of energy to gonad production with implications for the trade-off between somatic and gonad growth, as evaluated for female $S$. maximus from populations in environments with different salinities at spawning. For Baltic Sea S. maximus, spawning at a salinity of 6-7, the yearly energy allocation to gonad production in females amounted to $\approx 19 \%$ compared to $\approx 7 \%$ in marine conditions, adversely affecting the somatic growth at low salinities (Wallin \& Nissling, unpublished). Similarly, for female P. flesus in the Baltic Sea, somatic growth of the coastal spawning ecotype is poorer compared to the deep basin spawning ecotype due to higher egg production (Nissling \& Dahlman, 2010). For males however, there is no difference in somatic growth between the coastal- and deep-basin spawning $P$. flesus ecotype in the Baltic Sea $(F=0.72$, d.f. $=1, P>0.05)$ based on P. flesus caught off Gotland (SD 
28) (Florin \& Nissling, unpublished data). This is however not surprising given the difference in energy allocation to gonad production between male and female $P$. flesus. The gonado-somatic index (calculated as 100 gonad dry mass somatic wet $\operatorname{mass}^{-1}$ ) for females average $7.8 \%$ and $12.3 \%$ for deep-

222 basin spawning and coastal spawning Baltic Sea P. flesus, respectively (data from Nissling \& Dahlman, 2010), compared to $0,3 \%$ and $0,8 \%$ respectively for males (data from the present study), i.e. considerably lower energy allocation to gonad production for $P$. flesus males.

For males, fertilization capacity may be regarded as a question of spermatozoa motility in terms of duration, speed and direction or the in total distance covered, as well as the number of activated spermatozoa. Spawning at low salinities implies effects on both duration, speed and number of activated spermatozoa with effects on the fertilization rate as shown for flatfishes in the Baltic Sea; $S$. maximus, plaice Platessa platessa L. and P. flesus (Solemdal, 1973; Nissling et al., 2002; 2006). Data for P. flesus in ICES SD 25 and SD 28, i.e. the same areas in the Baltic Sea as in the present study (Table IX and X in Nissling et al., 2002), suggest similar duration of spermatozoa motility at a salinity of 7-15 for the coastal spawning $P$. flesus ecotype as for the deep basin spawning ecotype at 12-30, but with considerably shorter duration at lower salinities affecting the fertilization rate at $\leq 6.5$ but also at 7 (Fig. 5 in Nissling et al., 2002). Similar to as for S. maximus in the Baltic Sea (see Fig. 3 and Table II in Nissling et al., 2006), this suggests that also spermatozoa speed is crucial for successful fertilization of $P$. flesus as observations of initial swimming speed conducted to distinguish between the respective ecotype in the present study suggest (Fig. 2). However, neither of these studies was designed for evaluation of the relative importance of swimming speed, duration, direction and number of activated spermatozoa for the fertilization capacity. For an appropriate analysis of this, a more thorough methodology is required, i.e. in future studies e.g. a Computer-Assisted Sperm Analysis (CASA) systems with Assisted Sperm Morphology Analysis (ASMA) software enabling the estimation of a number of sperm motion parameters (see Mylonas et al., 2016) should be used to address adaptations according to low salinities. 
245 Studies of reproduction in marine fishes adapted to spawning at low salinities represents an interesting 246 field not only for evaluation of the relative importance of spermatozoa swimming performances for the

247 fertilization capacity of fishes in general, but also for mechanisms triggering the initiation of

248 spermatozoa activity as motility occur at also hypo-osmotic conditions (at a salinity of <10) as

249 opposed to at hyper-osmotic conditions in a fully marine environment. In this respect the role of 250 aquaporins shown to be involved in both spermatozoa activation and motion pattern (Boj et al., 2015)

251 should be considered. As pointed out by Alavi \& Cosson (2006), there is a wide range of variability in 252 the ionic composition of seminal plasma/spermatozoa in fishes, both between species and among populations within species, allowing for adjustments in mechanisms concerning spermatozoa motility, i.e. probably in response to varying salinity in accordance to the wide range of spawning habitats utilized by fishes. The present study suggests that in fishes of marine origin, the number of spermatozoa produced may be a key mechanism to sustain the fertilization capacity and thus the ability to reproduce in areas with low salinities.

\section{ACKNOWLEDGEMENTS}

Many thanks to I. Wallin and M. Ovegård for helping hands during sampling. The study received partly funding from BONUS INSPIRE, the joint Baltic Sea research and development programme (Art 185), funded jointly by the European Union's Seventh Programme for research, technological development and demonstration and the Swedish Research Council Formas. 
Alavi, S.M.H. \& Cosson, J. (2006). Sperm motility in fishes. (II) Effects of ions and osmolality: A review. Cell Biology International 30, 1-14.

Awata, S., Takeyama, T., Makino, Y., Kitamura, Y.\& Kohda, M. (2008). Cooperatively breeding cichlid fish adjust their testis size but not sperm traits in relation to sperm competition risk. Behavioral Ecology Sociobiology 62, 1701-1710.

Bagenal, T.B. (1966). The ecological and geographical aspects of the fecundity of plaice. Journal of the Marine Biology Association UK 46, 161-186.

Billard, R. (1986). Spermatogenesis and spermatology of some teleost fish species. Reproduction Nutrition Development 2, 877-920.

Boj, M., Chauvigné, F. \& Cerdà, J. (2015). Coordinated action of aquaporins regulates sperm motility in a marine teleost. Biology of Reproduction 93(2), 40:1-11. spermatozoa: racing ephemeral swimmers. Reproduction 136, 277-294. Sea: differences among demersal and pelagic spawners. Heredity 101, 27-38. shaping the genetic population structure of marine fishes; lessons from European flounder (Platichthys flesus L.). Molecular Ecology 16, 3104-3118. salinity: effects of ovarian fluid and egg presence. Canadian Journal of Fisheries and Aquatic 
Morisawa, M. \& Suzuki, K. (1980). Osmolality and potassium Ion: their role in initiation of sperm motility in teleosts. Science 210, 1145-1146.

293

Mylonas, C.C., Duncan, N.J. \& Asturiano, J.F. (2016). Hormonal manipulations for the enhancement of sperm production in cultured fish and evaluation of sperm quality. Aquaculture.

\section{http://www.diversifyfish.eu/uploads/1/4/2/0/14206280/mylonas 2016 aqua p1 online.pdf}

Nissling, A., Thorsen, A. \& da Silva, F.F.G. (2015). Fecundity regulation in relation to habitat utilisation of two sympatric flounder (Platichtys flesus) populations in the brackish water Baltic Sea. Journal of Sea Research 95, 188-195.

Nissling, A. \& Dahlman, G. (2010). Fecundity of flounder, Pleuronectes flesus, in the Baltic Sea Reproductive strategies in two sympatric populations. Journal of Sea Research 64, 190-198.

Nissling, A. \& Westin, L. (1997). Salinity requirements for successful spawning of Baltic and Belt Sea cod and the potential for cod stock interactions in the Baltic Sea. Marine Ecology Progress Series 152, 261-271.

Nissling, A., Johansson, U. \& Jacobsson, M. (2006). Effects of salinity and temperature conditions on the reproductive success of turbot (Scophthalmus maximus) in the Baltic Sea. Fisheries Research $\mathbf{8 0}$, $230-238$.

Nissling, A., Westin, L. \& Hjerne, O. (2002). Spawning success in relation to salinity of three flatfish species, Dab (Pleuronectes limanda), Plaice (Pleuronectes platessa) and Flounder (Pleuronectes flesus), in the brackish water Baltic Sea. ICES Journal of Marine Science 59, 93-108.

Solemdal, P. (1970). The reproductive adaptation of marine teleosts to water of low salinity. ICES International Council for the Exploration of the Sea, Committee Meeting F:30.

Solemdal, P. (1973). Transfer of Baltic flatfish to a marine environment and the long term effects on reproduction. Oikos (suppl.) 15, 268-276. 
Stockley, P., Gage, M.J.G., Parker, G.A. \& Møller, A.P. (1997). Sperm competition in fishes: the evolution of testis size and ejaculate characteristics. The American Naturalist 149, 933-954.

Stoss, J. (1983). Fish gamete preservation and spermatozoan physiology. In Fish physiology, Vol IXB

(Hoar, W.S., Randall, D.J. \& Donaldson, E.M., eds), pp. 305-350. New York: Academic Press.

Thorsen, A., Kjesbu, O.S., Fyhn, H.J. \& Solemdal, P. (1996). Physiological mechanisms of egg buoyancy in brackish water cod (Gadus morhua L.). Journal of Fish Biology 48, 457-477.

Ustups, D., Müller-Karulis, B., Bergström, U., Makarchouk, A. \& Sics, I. (2013). The influence of environmental conditions on early life stages of flounder (Platichthys flesus) in the central Baltic Sea. Journal of Sea Research 75, 77-84.

Westin, L. \& Nissling, A. (1991). Effects of salinity on spermatozoa motility, percentage of fertilized eggs and egg development of Baltic cod (Gadus morhua L.), and implications for cod stock fluctuations in the Baltic. Marine Biology 108, 5-9.

Voipio, A. (1981). The Baltic Sea. Elsevier Oceanographic Series no. 30. Amsterdam: Elsevier Scientific Company.

Wootton, R.J. (1990). Ecology of teleost fishes. Fish and Fisheries series 1. UK: Chapman \& Hall.

\section{ELECTRONIC REFERENCES}

FishBase. Froese, R. \& Pauly, D. (Eds) (2017). FishBase. World Wide Web electronic publication. www.fishbase.org (06/2017). Available at http://www.fishbase.org/Summary/SpeciesSummary.php?ID=1341\&AT=flounder (accessed 3 August 2017).

ICES. (2010). Report of the Workshop on Sexual Maturity Staging of sole, plaice, dab and flounder (WKMSSPDF), 22-26 February 2010, Ijmuiden, The Netherlands. ICES CM 2010/ACOM:50.

Available at www.vliz.be/imisdocs/publications/223184.pdf 
339 Table I. Sampling locations, depth range and salinity, and date of catches of spawning Platichtys flesus 340 in the present study. P and D refer to the ecotype with pelagic and demersal eggs, respectively, and 341 numbers to fish used in analysis. N.B. fish of the deep basin spawning P. flesus ecotype in the Baltic

342 Sea (BSDS) from SD 25 and SD 28 were pooled in analysis.

\begin{tabular}{|c|c|c|c|c|c|c|}
\hline ICES SD & Acronym & Date & Position & Depth (m) & Salinity & Number \\
\hline \multirow[t]{2}{*}{ SD $21 \mathrm{P}$} & KA & March 10 & $\mathrm{~N} 56^{\circ} 50^{\prime} \mathrm{E} 12^{\circ} 10^{\prime}$ & $\approx 40$ & $30-35$ & 49 \\
\hline & & March 17 & $\mathrm{~N} 57^{\circ} 02^{\prime} \mathrm{E} 11^{\circ} 51^{\prime}$ & $\approx 50$ & & \\
\hline SD $25 \mathrm{P}$ & $\overline{B S D S}$ & April 8 & $\mathrm{~N}^{\prime} 55^{\circ} 59^{\prime} \mathrm{E} 14^{\circ} 79^{\prime}$ & $\approx 70$ & $15-18$ & 17 \\
\hline \multirow[t]{2}{*}{ SD $28 \mathrm{P}$} & BSDS & April 23 & 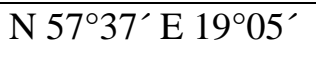 & $\approx 50-70$ & $10-12$ & 4 \\
\hline & & & 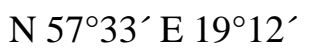 & & & \\
\hline \multirow[t]{2}{*}{ SD $28 \mathrm{D}$} & BSCS & April 22 & $\mathrm{~N}^{2} 7^{\circ} 43^{\prime} \mathrm{E} 18^{\circ} 92^{\prime}$ & $\approx 10-20$ & $7-7.5$ & 32 \\
\hline & & & N $57^{\circ} 42^{\prime}$ E $19^{\circ} 00^{\prime}$ & & & \\
\hline
\end{tabular}

Table II. Results of the GLM analysis of gonad dry mass (log) in relation to somatic mass (log) for

Platichtys flesus, according to the respective sampling area and ecotype; $\mathrm{P}$ and $\mathrm{D}$ refer to the P.flesus ecotype with pelagic and demersal eggs, respectively. Covariate appearing in the model was evaluated at the somatic weight $0.149 \mathrm{~kg}$.

\begin{tabular}{lrrrr}
\hline Area (ICES subdivision) & Mean & Std. error & \multicolumn{2}{r}{ 95\% Confidence interval } \\
\hline & & & Lower bound & Upper bound \\
\hline KA SD 21 (P) & -0.341 & 0.024 & -0.389 & -0.293 \\
\hline BSDS SD 25 and 28 (P) & -0.294 & 0.036 & -0.367 & -0.222 \\
\hline BSCS SD 28 (D) & 0.136 & 0.029 & 0.079 & 0.194 \\
\hline
\end{tabular}

\begin{tabular}{llll}
\hline Between subject effects & d.f. & \multicolumn{1}{l}{$F$} & \multicolumn{1}{l}{$P$} \\
\hline Area x somatic mass & 2,101 & 1.745 & $0.180^{*}$ \\
\hline Somatic mass & 1,101 & 106.3 & $<0.001$ \\
\hline Area & 2,101 & 86.95 & $<0.001$ \\
\hline
\end{tabular}

\footnotetext{
*interaction omitted in final analysis
} 
351 Fig. 1. The Baltic Sea and Kattegat with ICES subdivisions (SD) and positions of sampling locations

352 for Platichtys flesus; KA, BSDS (two sites) and BSCS (Table I). Kattegat SD 21 and Baltic Sea SD 353 22-32 (ICES statistical area 3; FAO fishing area 27, the Northeast Atlantic).

354 Fig. 2. Initial spermatozoa motility at different salinities of a) coastal- and b) deep-basin spawning 355 Platichtys flesus sampled in ICES subdivision 25 and SD 28 in the Baltic Sea; shown as the share of 356 males displaying spermatozoa motility as swimming slow, at intermediate speed or fast. $\mathrm{n}$ shows the 357 number of fish assessed. N.B. for the deep-basin spawning ecotype, no motility occurred at salinities 358 of 6 and 7.5 .

359 Fig. 3. Relationship between testis dry mass (log g) and somatic mass (log kg) for Platichtys flesus 360 according to area and ecotype; KA (Kattegat), BSDS (Baltic Sea deep-basin spawners) and BSCS 361 (Baltic Sea coastal spawners). BSDS fish sampled in ICES subdivision (SD) 25 and SD 28 pooled in 362 analysis. 
Sampling locations:

SD $21 \mathrm{KA}$

SD 25 BSDS

SD 28 BSDS \& BSCS
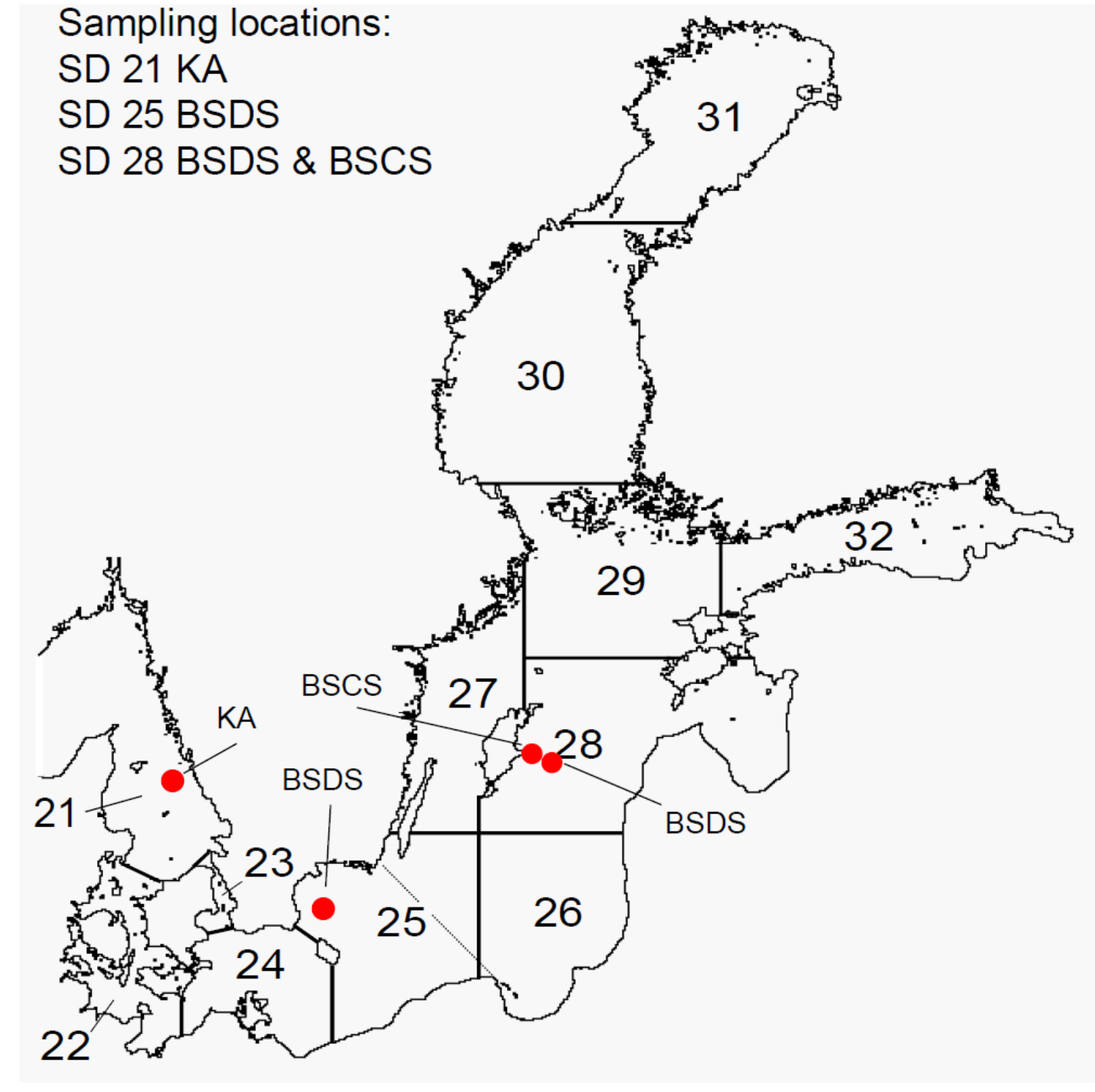
a)

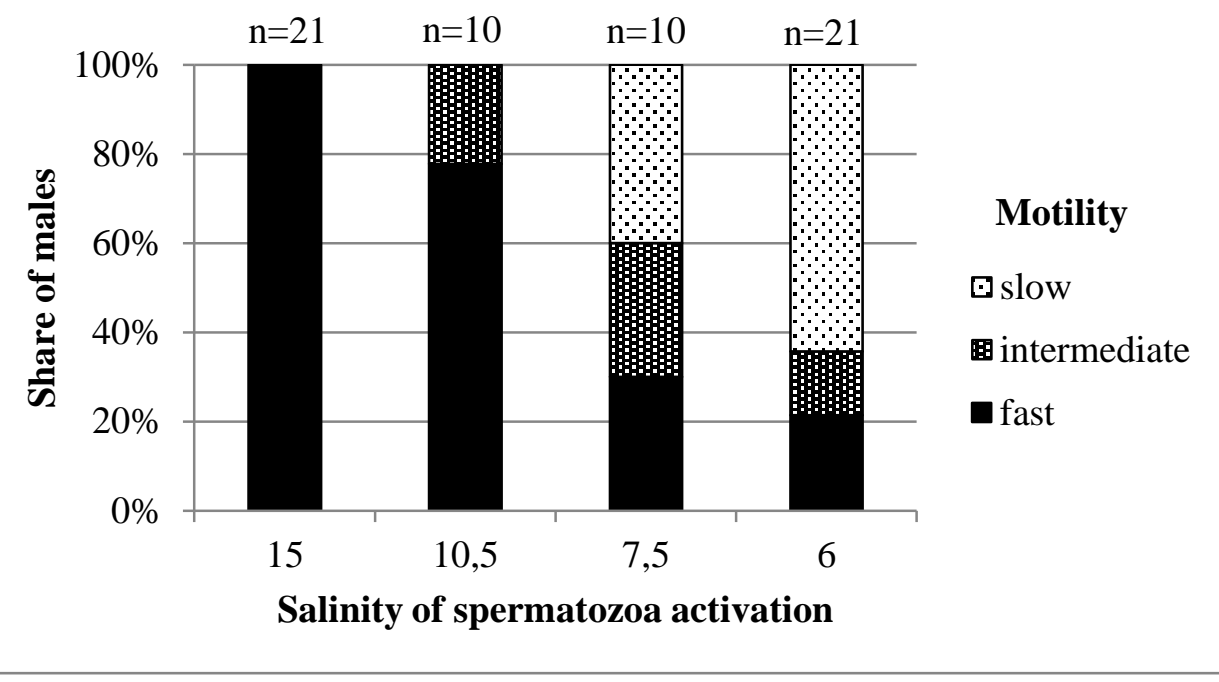

b)

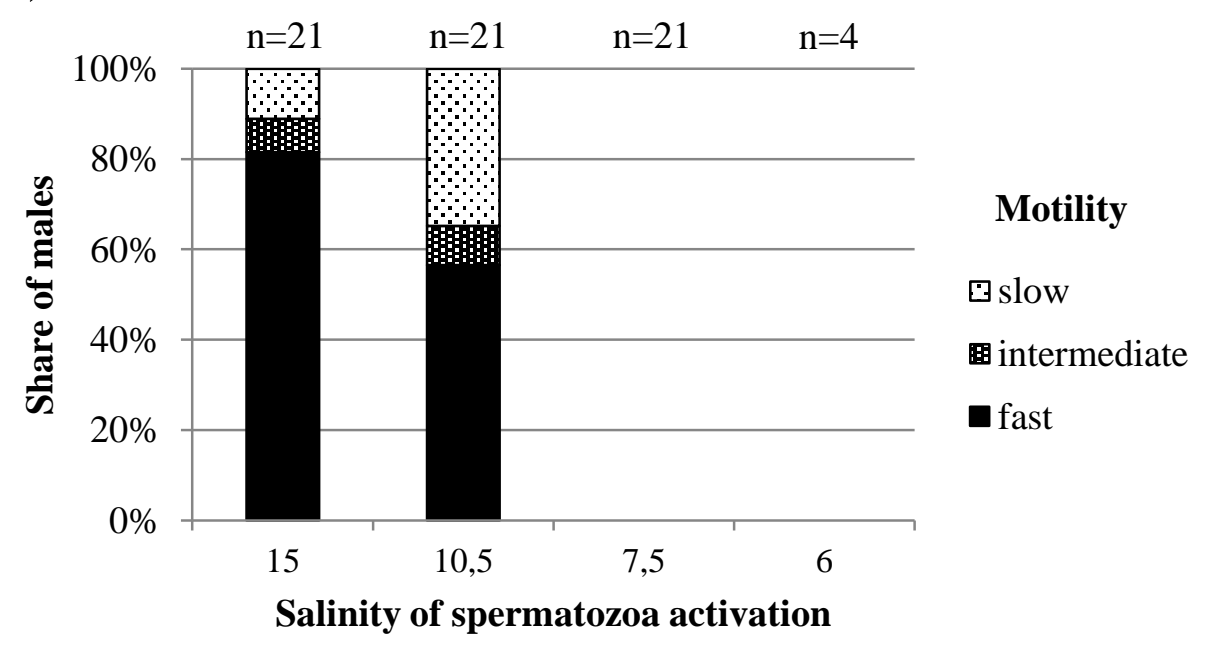

371 
373 Figure 3.

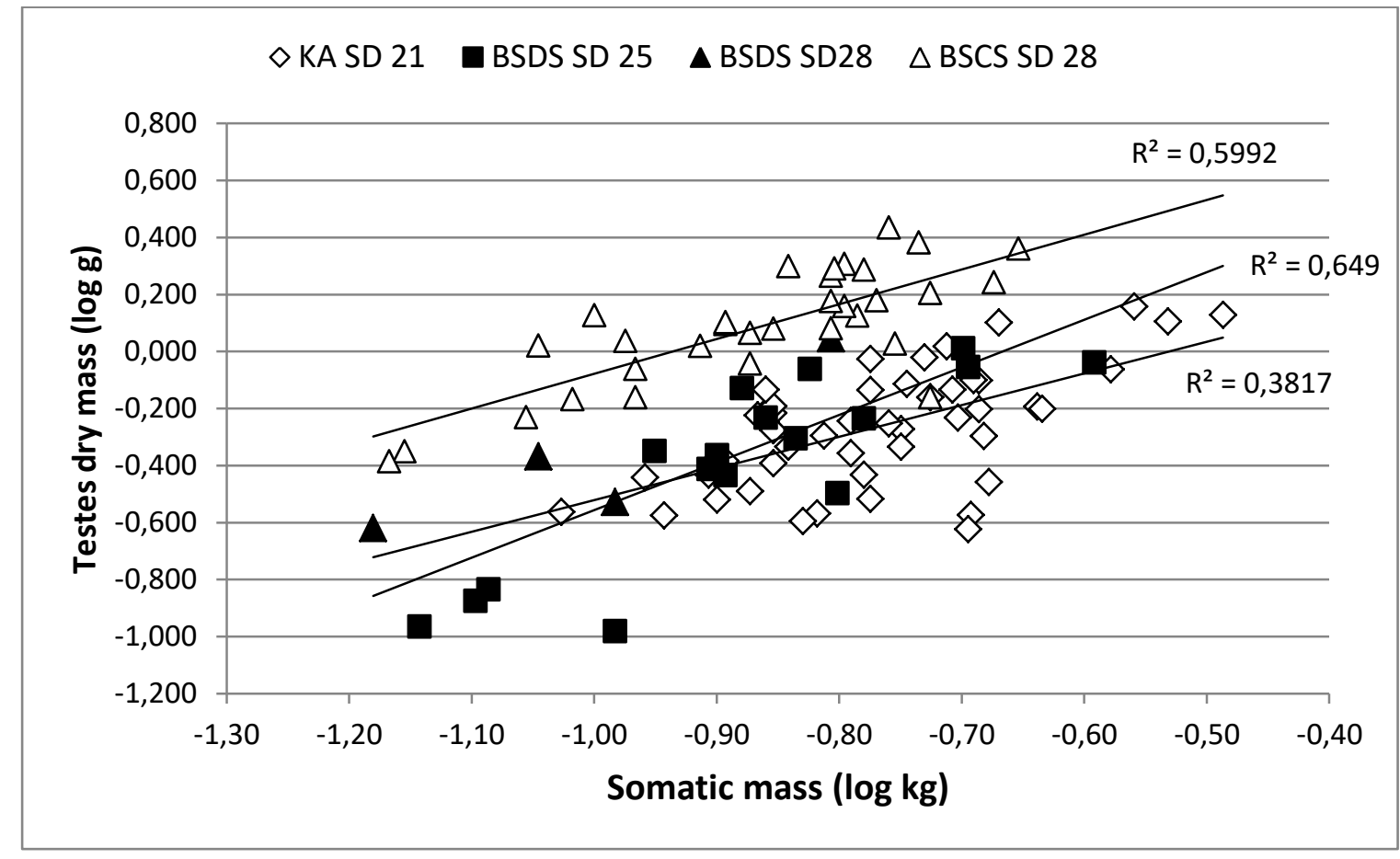

375 
377 spawning

\section{A. Nissling, R. Larsson}

379

e-mail: anders.nissling@ebc.uu.se

\section{Journal of Fish Biology}

Supporting Information:

382

383

384

385

386

387

388

389

390

Images of sampled testes in stage 3 (ICES 2010) for flounder Platichtys flesus sampled in ICES subdivision (SD) 21 (A), SD 25 (B) and SD 28 (C and D). KA refer to fish sampled in Kattegat (SD 21) spawning at a salinity of 30-35, BSDS to fish sampled in the Baltic deep basins (SD 25 and SD 28) spawning at a salinity of 10-18, and BSCS to fish sampled in coastal areas (SD 28) spawning at a salinity of $\approx 7$ (Table I; Fig. 1). Shown are examples of testes that were omitted in analysis based on color and shape as not being in early stage 3 (see ICES 2010), and testes for a $26 \mathrm{~cm}$ (total length) fish from the respective area/population (KA, BSDS and BSCS); the size of frames is the same for all images. N.B. the photos have been adjusted to show images at the same magnification. 
A)

KA SD 21
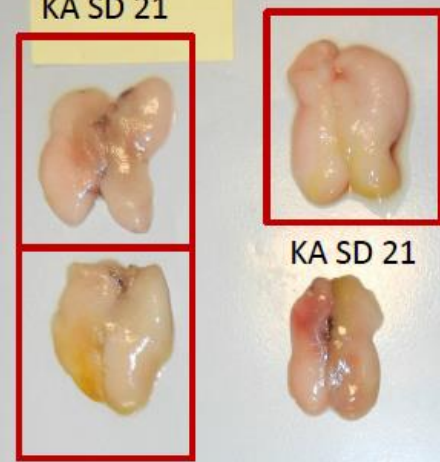

KA SD 21

KA SD 21

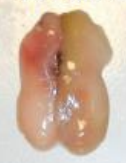

KA +

391

392 


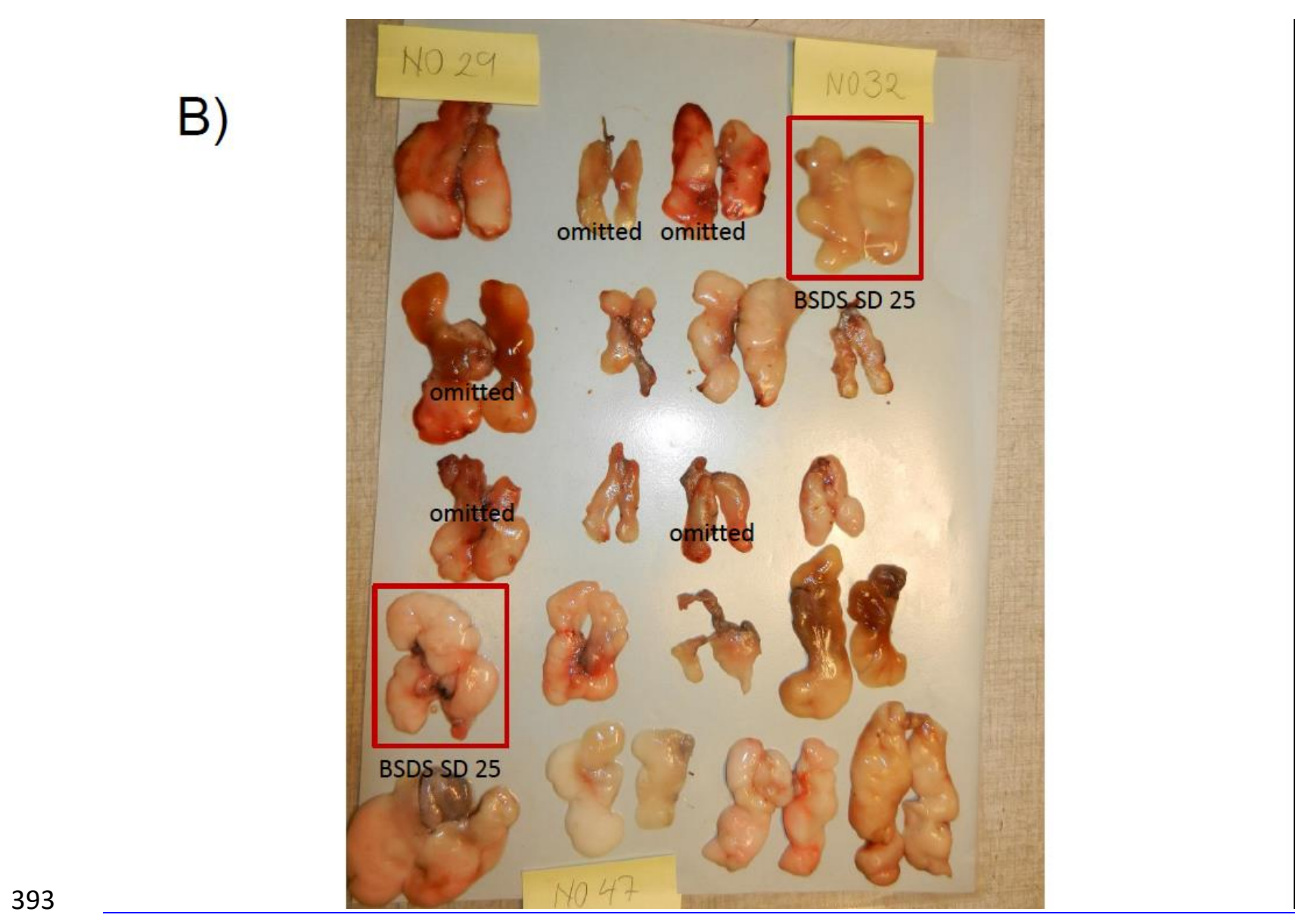

394 


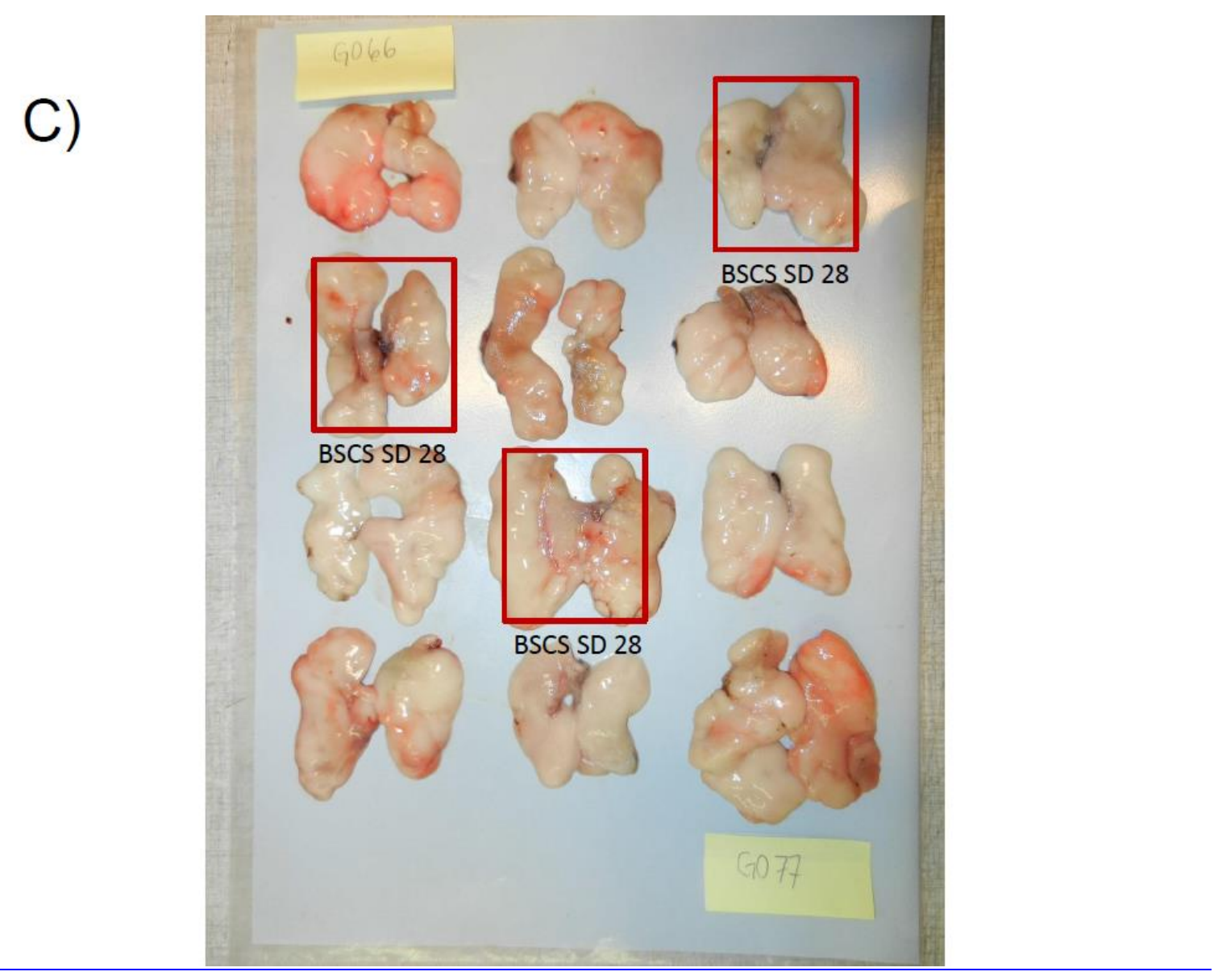

395

396 
D) 